\title{
Supporting Students' Reasoning About Multiplication of Fractions by Constructing an Array Model
}

\author{
Ronal Rifandi ${ }^{1)}$ \\ 1) Adrkia College of Education (STKIP Adrkia) \\ Corresponding author: ronal_rifandi@yahoo.co.id
}

\begin{abstract}
The aim of the research is to support students in constructing an array model as a bridge from their informal knowledge to the formal one in understanding the part-whole relation concept. The partwhole relation concept is important for students to reason about multiplication of fractions. Realistic Mathematics Education which is in Indonesia adapted as Pendidikan Matematika Realistik. Indonesia (PMRI) is used as an approach in designing a series of lessons. For this purpose, bypothetical learning trajectory (HLT) became the base for conducting a teaching experiment and designing its learning materials. The research was conducted in the fifth grade of SD Al Hikmah Surabaya, an elementary school in Indonesia, with five students as the participants. The collected data were qualitative data in the form of students' written works and the transcript of video recording during the lesson. The data were analyzed retrospectively by confronting the conjecture of students' thinking in the HLT with the fact in the teaching experiment. The result of the research shows that most students could use the contextual problem in promoting their ability on constructing their own array model to reason about part-whole relation.
\end{abstract}

Keywords: Fractions Multiplication, RME, Design Based Research, HLT

\section{Introduction}

Students start to express ideas about fractions in many situations in their daily life. It is earlier than when it is taught in the classroom (Smith, 2002). An example of the situation is when they share candies or a cake with their friends. They informally build their own perception of fractions. In the next stage, they express their initial knowledge in the classroom and they find something called "fractions". Despite its frequent appearance in daily life, however, the topic of fraction is very complicated. There is more than one interpretation of fractions and each of them has its own characteristic. The first expert who distinguished the five constructs of fractions was Kieren (in Charalambous \& Pitta-Pantazi, 2007). He identified fractions as part whole relations, ratio, quotient, measure and operator. These five constructs are also used and elaborated more in many other studies (Pantziara \& Philippou, 2012; Behr, M. J., Harel, G., Post, T., \& Lesh, R., 1992).

In a recent study, Smith (2002) refers to fractions as a quotient, divided quantity, ratio and proportion. About thirty years ago, Freudenthal (1983) also explained about the multiple interpretations of fractions. He elucidated three interpretations of fractions in 
his book Didactical phenomenology of mathematical structures. First, he explained about fraction as fracture. Within this interpretation, fractions appear as a result of dividing a whole unit in some parts. The whole unit here can be definite and indefinite (Freudenthal, 1983). Second, he described fractions that can be used in comparison, especially in indirect comparison where a third object is used to mediate between the two objects to be measured. Third, he stated fractions that can be used in an operator.

Moreover, in terms of mathematical reasoning, Lithner (2008, in Vale et al., 2016) found that "reasoning in mathematics classroom is often imitated when algorithmic reasoning is memorised and contained within specific problem or exercise settings". In a conventional way of teaching and learning we could stated that most students tend to memorise the procedure and struggle in developing the understanding. We commonly found that in reason about fractions students only focus on the formal or abstract way of solving fractions' operation.

According to the explanation above, we can conclude that we need to teach fractions properly to the children so that they could develop their understanding in this complicated topic. In order to develop that understanding,a teacher could choose Realistic mathematics education (RME) which is in Indonesia adapted as Pendidikan Matematika Realistik Indonesia (PMRI)_as the learning approach. For the limitation, in this study we focus on multiplying a fraction with another fraction. Our aim in this study is to support students' reasoning about multiplication of two fractions by constructing an array model. We formulate a research questions as follows: "How can context support the emergence of an array model to support students' reasoning of multiplication of two fractions?”.

\section{The Use of Context}

Treffers (1987, as cited in Keijzer, 2003) stated that in teaching mathematics a teacher needs to consider the initial knowledge of students and relates it to the realistic contexts as a base for the learning activity. The realistic contexts which consist of meaningful problems give students a chance to build their understanding of the mathematics (Greeno, Collin \& Resnick, 1996, as cited in Keijzer, 2003). Furthermore, in the Realistic Mathematics Education (RME) approach, the mathematisation of meaningful problems becomes a tool for students to construct formal notions about the concept (Van den Heuvel-Panhuizen, 1996).

Moreover, Freudenthal (1991) suggested that mathematics teaching and learning should be a process of "reinvention" by the students instead of just transferring the knowledge from the teacher to the students. The role of the teacher is to support students in this learning process.

According to the explanation above, it is important to use a meaningful context that can be explored as the foundation of the concept formation. Instead of starting to explain the abstract and procedural knowledge about multiplication of two fractions, in the study, students are engaged with the context about a "sharing a chocolate block and dividing a martabak telur (Javanese traditional food)".

\section{The Emergence of Model}

The emergence of model is one of the five tenets of RME. It is important because in this study we want to know more about the use of models in supporting students' understanding of fractions. Gravemeijer (1994) stated that basically models are used as a 
concrete starting point for developing a formal notion of a concept in mathematics. In Figure 1, there are the four levels of models that Gravemeijer (1994) proposes.

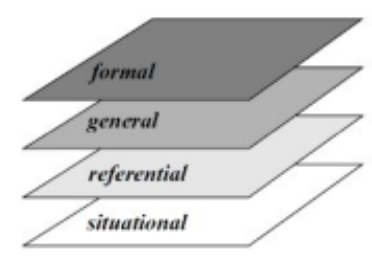

Figure 1. Four levels of emergent modeling (Gravemeijer, 1994)

Gravemeijer described those levels as follows:

- The level of situations, where domain specific, situational knowledge and strategies are used within the context of the situation (mainly out of school situations);

- A referential level, where models and strategies refer to the situation which is sketched in the problem (mostly posed in a school setting);

- A general level, where a mathematical focus on strategies dominates the reference to the context;

- The level of formal arithmetic, where one works with conventional procedures and notations.

(Gravemeijer, 1994, p. 101)

In addition, the modeling in the referential level uses models as a representation of the activity in the instruction and in the general level the models become "models for" which are used in problem solving. This is independent of the situation (Gravemeijer, 1994). Furthermore, Gravemeijer (in Fosnot \&Dolk, 2002) stated that "The shift from model of to model for concurs with a shift in students' thinking, from thinking about the modeled context situation, to a focus on a mathematical relations" (p.74). It means that in the learning a teacher should provide the students with a context that can be modeled by the students, after which students, guided by the teacher will move to use the models as a tool for problem solving in a more general situation.

In this study, the array models are used to support students to develop their understanding of multiplication of two fractions and solved problem. Therefore, we design a sequence of lessons to overcome students' difficulties in multiplication of two fractions grounded with the RME approach. The focus is on using models to support students' development in their understanding.

\section{Research Methods}

This study took place in SDI Al Hikmah, an Islamic Elementary School in Surabaya, East Java. The participants in the study were a small group of five students in the grade 5. As mentioned beforehand the research approach used in this study is a design-based research of three phases: preparation, teaching experiment and retrospective analysis. We collected data about students' thinking and also their learning 
process. All of the activitieswere recorded in a video registration supported with the students' written work. We conducted a small discussion with the students about the activities and their thinking after each activity and it was included in the field notes of the researcher.

To validate the data collection;we utilized data triangulation by collecting data with different methods such as observations, interviews and students' written work. In addition, to improve the reliability of the data collection, this study used video registration as the main methods in collecting the data to ensure that it is independent from the researcher.

\section{Design Based Research}

The aim of the research is to facilitate the emergence of an array model functioning as a bridge for the students from their informal knowledge to the formal one in understanding the part whole relation concept. In order to reach the aim and answer the research question, we make a design of learning sequences equipped with teaching and learning materials.

Based on the explanation above, the suitable approach for this design is a design based research (DBR) since we have an innovative goal, improving the teaching and learning. Bakker and van Eerde (2015) stated that "DBR typically has an explanatory and advisory aim, namely to give theoretical insight into how particular ways of teaching and learning can be promoted" (p. 4). It means that the focus of this study is on understanding the process of teaching and learning grounded by the theory so that it can support students' development. In this study, further, we combine both the development of the theoretical framework and that of local instruction theories (Gravemeijer \& Cobb, 2006).

In addition, the reason for choosing DBR is the two DBR's characteristics: prospective and reflective components that need not to be separated by a teaching experiment" (Cobb, et al., 2003, in Bakker and van Eerde, 2015). The prospective component that we make in the form of the conjectures of the learning activities is confronted with the real fact in the learning activities that we observe. The reflective component is when we evaluate and make a reflection after we have collected and analyzed the data. It means that we can make a revision of our prospective components of the next lesson due to the evaluation and reflection of the previous lesson.

Furthermore, in the present study, we follow the three phases of the design based research. They are preparing for the experiment, experimenting in the classroom, and conducting a retrospective analysis (Gravemeijer and Cobb, 2006).

\section{Hypothetical Learning Trajectory}

In this study, we elaborate a hypothetical learning trajectory of learning multiplication of a fraction with another fraction by focusing on the use of the model to support students to develop their understanding of the topic. Simon (1995) stated that there are three main components in the hypothetical learning trajectory (HLT): the learning goal, the learning activities and the hypothetical learning process. The HLT could be the proper tool in preparing a learning instruction, become the scheme in explaining students' learning and also as the base to describe students reactions to the lesson (Wright, 2014). In this study, we describe briefly about the starting point of the students where we explain about the pre knowledge that we expect students already have before starting the learning activity in this design. Moreover, for the hypothetical learning 
process, we not only describe the conjecture of students' thinking, but also provide teacher reactions to the conjecture. This teacher reaction will be used as a help for the teacher in the teaching experiment phase and it is elaborated more in the teacher guide for each lesson.

The following are the HLTs used in this study:

1. Learning goals. Students are able to construct their own array and use it in solving the taking a part of a part of a whole problems.

2. Starting point. Students already learned about how to do a partitioning properly and give labels to the result of the partitioning activity in fraction notation. And, they have already introduced to the use of an array model to help them in solving problems about taking a part of a part of a unit.

3. Description of the activity, conjectures of students' thinking, and teacher reactions:

There are two activities in in this lesson. The first one is about sharing martabak telur, a Javanese traditional food and the second one is about choosing an appropriate array to solve a problem. The aim of the activities is addressing the students' ability to construct their own array in solving the problem. First, students will work in pair on the problems of first problem followed by a class discussion after each problem. Next, the teacher asks the students to work on the second problem and followed by a class discussion.

Activity 1

The Hafidz's mother makes a martabak telur for the desert at lunch. However, Hafidz went home lately after doing the exercise in the morning. They just found $\frac{\mathbf{1}}{\mathbf{2}}$ of the martabak telur telur in the kitchen. Hafidz eats $\frac{\mathbf{1}}{\mathbf{4}}$ of the left-martabak telur. What part is that if we compare to the whole martabak telur? (Hint: You can draw a picture to help you in solving this problem).

Write your answer in fraction notation!

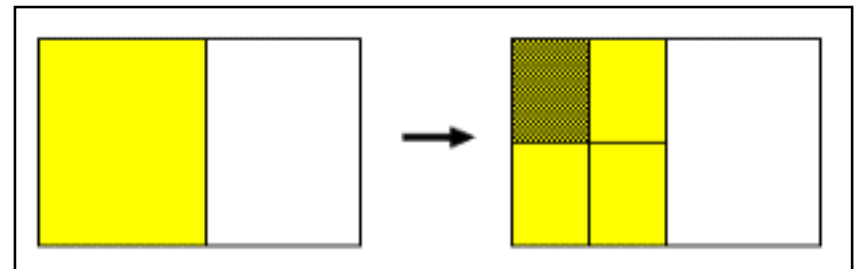

Figure2. Representation of a Whole Martabak Telur in a Rectangle

The conjectures of students' strategy of the problem in activity 1 can be described as follows:

- The students represent the whole martabak telur in a rectangle as a starting point. Then they divide it into two and shade one of it as the representation of the martabak telur left in the kitchen. Because they know that Hafidz eat $\frac{\mathbf{1}}{\mathbf{4}}$ of 
the remaining martabak telur so they divide the shaded area into four equal parts and indicate one part of it as the part eaten by Hafidz.

- To get the answer to the problem, the students need to compare the Hafidz's part with the whole martabak telur. They get $\frac{1}{4}$ of $\frac{1}{2}$ of a whole martabak telur. The students may not get the final solution since they struggle on how to determine the fraction notation of Hafidz's part compare to the whole martabak telur. Some of the students maybe just count the shaded area not the blank one, so they get $\frac{1}{4}$ as the false answer.

- The students use the representation of the half of the martabak telur in a rectangle as a starting point and divide it into four (see Figure 3). But, they do not relate the parts with the whole cake as the unit. They cannot determine the whole unit and as an effect they cannot come up with a fraction notation for the Hafidz's part respect to the whole martabak telur.

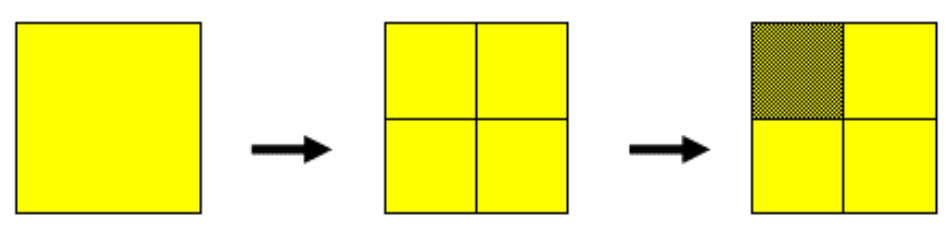

Figure 3. Representation of a Half of Martabak Telur as a Starting Point

Teacher Reactions and Discussion

If the conjecture of students who start with the representation of the whole martabak telur but they cannot determine the fraction notation of Hafidz's part happens, the teacher can invite the students to think about the Hafidz's part respect to the whole martabak telur. The teacher can ask the student that "Can you think about how many times the small part (the Hafidz's part) fit into the whole martabak telur representation?"'Then, they can draw a dot line to help them (see Figure 4).

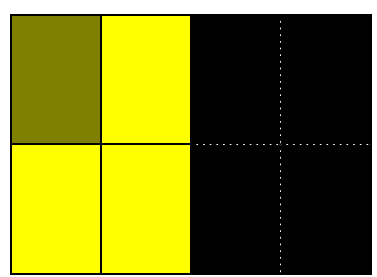

Figure 4. Making Dot Lines inside the Rectangle

Students may answer that the fraction notation of the Hafidz's part is $\frac{\mathbf{1}}{\mathbf{7}}$ which is not correct. The teacher can suggest students to think again by posing the question such as "If we only arrange 7 small parts of the martabak telur then will they form a rectangle?" Since the whole martabak telur is represented in a rectangle so there is one more small part needed. Therefore, the Hafidz's part must fit 8 times in the rectangle and one small part is equal to $\frac{\mathbf{1}}{\mathbf{8}}$ of the whole martabak telur.

In addition, if the second conjecture of students' answer to problem 1 happens, the teacher can ask the students about how to draw the whole martabak 
telur if we have a half of it. May be, the students will realize that they need a half more to complete the rectangle as the representation of the whole martabak telur. Furthermore, the discussion can be continued to determine the fraction notation for Hafidz's part which is already explained in teacher reaction of the first conjecture.

After finishing the class discussion about the first problem, the teacher asks the students to work on the second problem.

Activity 2

Three students try to solve the problem 1 by drawing a rectangle on grid paper. As you can see in the following:

Student-A

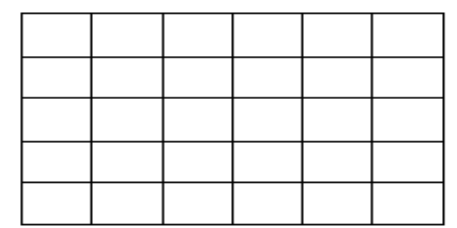

Student-B

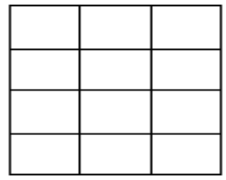

Student-C

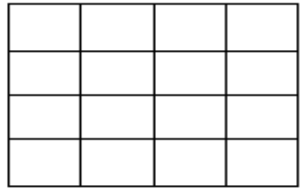

Which drawing do you prefer to solve the problem? Explain your answer!

The conjectures of students' strategy of the problem in activity 2 can be described as follows:

- The students will try to apply the divide and the shade strategy for all samples. Perhaps, they will notice that for the students A and B, they cannot divide the array properly. The only one that might be an easy help to solve the problem is the array of students C. It will come up with $\frac{1}{8}$ or $\frac{2}{16}$ as the result.

Teacher Reactions and Discussion

The problem in activity 2 will lead students to think about the dimension of the array. We hope that they will recognize the idea of using an appropriate array size, which depends on the number used in the problems. Moreover, the teacher also can invite students to compare the answer to this problem with the solution that has been discussed in activity 1 . If they get confused because of the different drawing and the different fraction form, then the teacher can bring the idea of fraction equivalency to the students. It also can be used to strengthen the students' understanding that in taking a part of a part of a whole, and we need to consider the result respects to the initial whole unit.

\section{Results and Discussion}

In this part, we will provide an overview about the initial knowledge of the students that already explored in the previous lesson as a starting point for the lesson 
which is described in this paper. Further, we will explain about the context, the task and the idea behind the activity 1 and 2 of the lesson. Then, we will describe the retrospective analysis by confronting the HLT with the actual learning activity in the teaching experiment phase.

In the previous lesson the students already experienced the idea of partitioning and solving problem which involved the given array figures. The story in the previous activity was about three children, Aufa, Siraj and Hafidz who share a chocolate block equally. Then, Hafidz shares his parts with his sister Nazifah. The instruction is indicated in the given array figure the part for Nazifah and what part of the block of the chocolate did Nazifah get? Based on the result and the analysis of the lesson, it shows that the students could use the given array models to convince about the idea of part-whole relationship and to make the fraction notation of it (Rifandi et al., 2014).

The following are the result and discussion about 2 activities in the lesson. The first one is about sharing martabak telur and the second one is about choosing an approriate array.

Activity 1: Sharing Martabak Telur

In this activity the context was about sharing a martabak telur. In the story, it is stated that the Hafidz's mother made a martabak telur. However, because Hafidz come home late, he just found a half of that martabak telur, then he eats a quarter of it. The students' task in the first problem was to determine what part of the martabak telur that was eaten by Hafidz respects to the initial martabak telur. The researcher gave hints that the students could make a drawing to help them.

The goal of this activity was to give more chances for the students in dealing with the taking a part of a part of a whole problem within a context. In this activity, we did not provide the students with the drawing. Our intention was that the students started to construct their own array model. In our expectation of the initial HLT, there would be two strategies of the students. First, they start to draw the whole martabak, telur and the second they start to draw the martabak telur available before Hafidz eats it.

To solve the problem in activity 1 , based on our observation of the video registration, all of the students started to make a drawing to help them in solving the problem (see Transcript 1).

Transcript 1

Adrian : (Draw a rectangle and split it into 2 big parts and then split each of it into four equal parts).

The researcher : Can you explain your drawing?

Adrian : This part is already eaten (indicating a half of the rectangle by his hand). Then, Hafidz eats a quarter of the leftover. So it means 1 over 4 of 1 over 2.

The student drew a square and split it up into two parts first and then divided it into four parts, then shaded one small piece of the last partition. We can interpret that the student could construct his own array by showing a new quantity as the result of the first partition and take a part of the new quantity.

We triangulate the data collected in the Transcript 1 above by providing student's written work on this problem (see Figure 5a). These two data show a consistency in which we can see in his work, the student shade one small pieces of the array they have constructed. 
As a compliment for the analysis above, we also pointed at different strategy used by other students as seen in Figure $5 \mathrm{~b}$ and c. In our interpretation, Izmi drew a small rectangle first and drew another seven small rectangle in order to complete the martabak telur as the initial martabak telur. Abdul also drew a rectangle and then he split it up into two and then made it became an array with dimension $4 \times 8$.

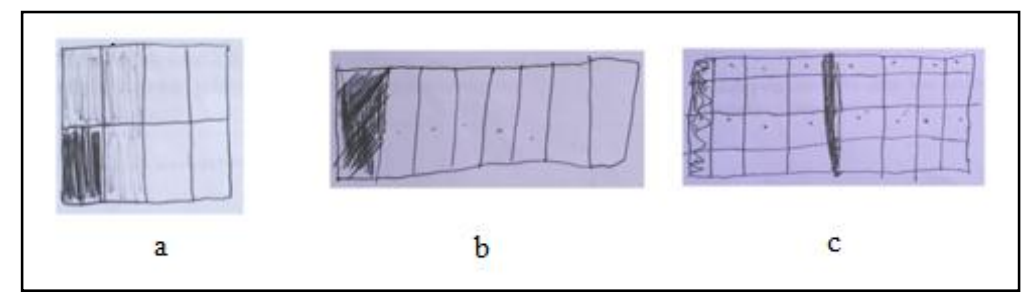

Figure5. Students' Answers of Problem 1 in Activity 1

Based on students' strategies above, we could see that all of our conjectures in the initial HLT happened. As a conclusion, it implies that the students grasped the idea of part-whole relationship well. They knew that they should represent the whole martabak telur in order to determine the fractional notation of the intended part of the problem.

Furthermore, to find the final solution of problem 1, there were two different strategies that were used by the students. First, as we conjectured, they calculated the number of small pieces in the drawing by multiplying the dimension, they got $\frac{1}{8}$ as the answer (see Figure 6 a). Second, they did two multiplication steps, at first they multiplied the total number of small pieces in the initial martabak telur with $\frac{1}{2}$ and then multiplied the result with $\frac{1}{4}$ to get the pieces that were eaten by Hafidz. Furthermore, they related the last result to the total number of the small pieces in the initial martabak telur, they came up with $\frac{1}{8}$ as the answer (see Figure 6 b). The second strategy we described here was not in our conjecture.

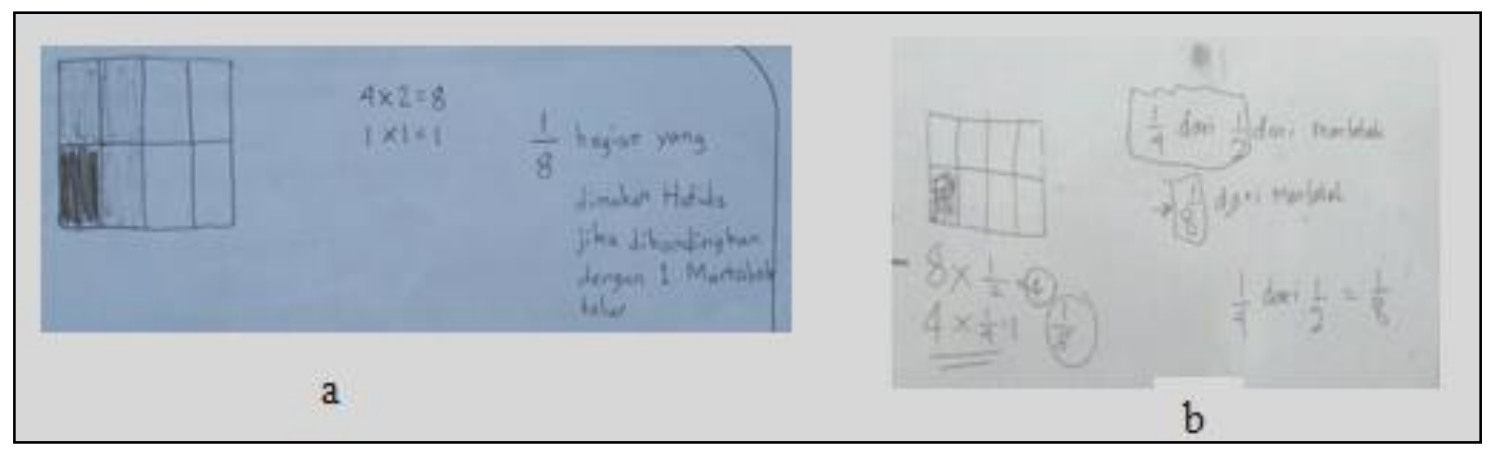

Figure 6. Two Strategies in Solving Problem in Activity 1

The students who solved the problem with the second strategy above indicate that they started to work with fraction operation in solving this problem. Partially, they tried to relate the "taking a part of" into the multiplication involving fractions. However, we still did not have enough data to interpret their thinking. For example, why they wrote $8 \times \frac{1}{2}$ instead of $\frac{1}{2} \times 8$ since the meaning between the two operations in this example is different. 
Activity 2: Choosing an appropriate array

Furthermore, the next activity was to choose one of the three given arrays that are already made by three pupils in the story, $\mathrm{A}, \mathrm{B}$ and $\mathrm{C}$ with different dimensions to solve the problem in activity 1 . The dimensions of the arrays in the activity 2 were $5 \times 6,4 \times 3$, and $4 \times 4$ respectively.

The aim of this activity was to assure that the students recognized the idea of choosing an appropriate dimension of the array that they used to help them in solving the taking a part of a part of a whole problems. We expected that the students would do a trial and error strategy where they tried to apply the taking a quarter of a half of the martabak telur on the three arrays.

Based on students' written works and also based on the video registration, we can see that all of the students chose that the last figure was the easiest tool that could help them in solving the problem. However, they still struggled to explain the reason why they chose the last figure. They said that because the first figure has too many small pieces, then they researcher consulted their answer, "if the first has too many small pieces, why they did not choose the second figure?" The Transcript 2 is the discussion about the reason why they could not choose the second figure in the problem sheet (figure B).

Transcript 2

The researcher : Why don't you choose the student B. If the reason is because too many small boxes, why don't you choose the student B since [his or her drawing] has the least number of small box in it. Why it is not?

Abdul : Hmm...

The researcher : Before, you said that because the student A's figure has too much small box, so then it mean student B as the answer right? [Why not?]

Adrian $\quad:$ Because the student $B$ has least number of the small boxes in it.

Arfan : Because the quarter... em a half of the quarter cannot be shown in the figure.

Abdul : Yes, we cannot show a half of the quarter in the figure.

The researcher : Okay. Can you repeat it loudly Arfan?

Arfan : Because we cannot show a quarter of the half in the figure.

The researcher : We cannot show in the figure.

Arfan : Yes.

Based on the Transcript 2 we can see that at first the students said that the second figure (figure of student $\mathrm{B}$ on the problem sheet) has least number of small pieces. These answers imply that they still could not grasp the idea of using the suitable dimension of the array properly. However, one of them recognized a reason that they could not use the figure of student B because it could not show the quarter of a half of the martabak telur.

As a compliment to the transcript, we found in students' written work, there is student came up with the idea that the last figure was easy to divide to produce even number (see Figure 7). 


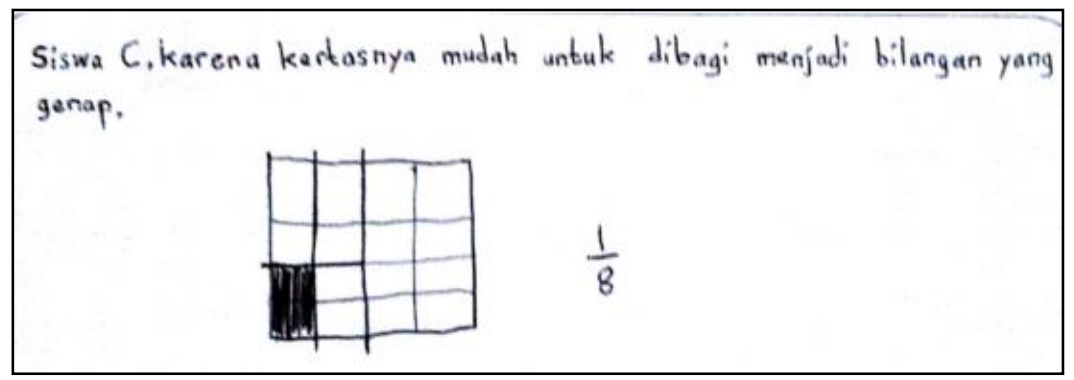

Figure 7. Students' Written Work on Problem in Activity 2

The opinion above is closer to the core idea of this activity. After the discussion as transcribed in the Transcript 2 the students could recognize that they could show the half of the martabak telur easily and so did for the quarter of the half of the martabak telur in the last figure (figure of student $\mathrm{C}$ on the worksheet). We could see that the data collected through different method support each other so that we could derive a complete figure of the learning process of the students.

Based on the analysis of the students' written works and the video registration about the activity 2 beforehand, we conclude that the students could grasp the idea of using the appropriate dimension of the array models that could be used as a tool in solving the taking a part of a part of a whole problem. All of the students could reason about the solution after the researcher lead a discussion to addressing this idea.

Furthermore, we will compare what other studies found about using context and model in support students to develop their mathematical understanding especially in the topic of fractions. Nasution et al. (2014) found that the idea of using models in the form of students' visualitation support them to learn about proportion. Moreover, Lestiana et al. (2014) conducted a design research about addition of fractions and her study suggests that the use of models (paper strip and bar model) help students to develop their understanding about addition of fractions. Both of the studies metioned beforehand use realistic mathematics education which is started with a contextual problem. And, the present article also shows the same result that the RME contexts could support students to cnstruct their own model to solve the mathematics problem.

\section{Conclusion}

Generally, based on the analysis of the students' written works and the video registration of this lesson, we conclude the following points. First, the context about sharing martabak telur supported the students in constructing their own array. It helps when the students determine the part and the whole unit in their drawing. Second, through the activity of choosing the right array figure in solving the martabak telur problem, the students recognized about the use of an appropriate array dimension to be used in reasoning about fractions multiplication. Third, the students could solve the taking apart of a part problem, although the initial whole unit was not mentioned explicitly. In addition, the students were able to represent the taking a part of apart in a suitable array model and determine the fractional notation of the result of the partition. 


\section{Bibliography}

Bakker, A., \& van Eerde, D. (2015). An introduction to design-based research with an example from statistics education. In Approaches to qualitative research in mathematics education (pp. 429-466). Springer Netherlands.

Behr, M. J., Harel, G., Post, T., \& Lesh, R. (1992). Rational number, ratio, and proportion. Handbook of research on mathematics teaching and learning, 296-333.

Charalambous, C. Y., \& Pitta-Pantazi, D. (2007). Drawing on a theoretical model to study students' understandings of fractions. Educational Studies in Mathematics, 64(3), 293-316.

Fosnot, C. T., \& Dolk, M. L. A. M. (2002). Young mathematicians at work: Constructing fractions, decimals, and percents. Portsmouth: Heinemann.

Freudenthal, H. (1983). Didactical phenomenology of mathematical structures (Vol. 1). Springer.

Freudenthal, H. (1991). Revisiting mathematics education-china lectures. Dordrecht: Kluwer Academic Publishers.

Gravemeijer, K. (1994). Developing realistic mathematics education. Utrecht: CD-B press/ Freudenthal Institute.

Gravemeijer, K.P.E \& Cobb, P. (2006). Design research from a learning design perspective. In: Van Den Akker, J., Gravemeijer, K.P.E McKenny, S. \& Nieveen, N (Eds.). Educational Design Research. New York: Routledge.

Keijzer, R. (2003). Teaching formal mathematics in primary education. Fraction learning as mathematising process. CD-Beta Press, Center for Science and Mathematics Education.

Lestiana, H. T., Abadi, Budiarto, M. T., Abels, M. J., van Eerde, D. (2014). Promoting students' understanding of the addition of fractions. In R. I. I., Putri (Ed.), The second South East Asia Design/ Development Research (SEA-DR) International Conference (pp. 142-151). Palembang: Sriwijaya University.

Nasution, A. A., Amin, S. M., Lukito, A., Abels, M. J., Dolk, M. (2014). Educational Design Research: Supporting fifth-grade students to learn about proportion . In R. I. I., Putri (Ed.), The second South East Asia Design/ Development Research (SEADR) International Conference (pp. 43-51). Palembang: Sriwijaya University.

Pantziara, M., \& Philippou, G. (2012). Levels of students"conception" of fractions. Educational Studies in Mathematics, 79(1), 61-83.

Rifandi, R., Budiarto, M. T., Lukito, A., Abels, M. J., Dolk, M. (2014). Developing grade five students understanding of multiplication of two fractions trough taking a part of a part of a whole activity. In R. I. I., Putri (Ed.), The second South East Asia Design/ Development Research (SEA-DR) International Conference (pp. 272-278). Palembang: Sriwijaya University.

Simon, M. A. (1995). Reconstructing mathematics pedagogy from a constructivist perspective. Journal for research in mathematics education, 114-145.

Smith, J. P. (2002). The development of students' knowledge of fractions and ratios. In B. Litwiller, \& G. Bright, Make Sense of Fractions, Ratios, and Proportions (pp. 3-17). Reston, VA: National Council of Teachers of Mathematics.

Vale, C., Widjaja, W., Herbert, S., Bragg, L. A., \& Loong, E. Y. K. (2016). Mapping Variation in Children's Mathematical Reasoning: The Case of 'What Else Belongs?'. International Journal of Science and Mathematics Education, 1-22.

Van den Heuvel-Panhuizen, M. (1996). Assessment and realistic mathematics education. Utrecht: CD-B Press / Freudenthal Institute, Utrecht University.

Wright, Vince. (2014). Towards a hypothetical learning trajectory for rational number. MathematicsEducation Research Journal, 635- 657. 